RAPER, K. B. \& Quinlan, M. S. (1958). J. gen. Microbiol. 18, 16-32

\title{
Acytostelium leptosomum: A Unique Cellular Slime Mould with an Acellular Stalk
}

\author{
BY K. B. RAPER AND MILDRED S. QUINLAN \\ Departments of Bacteriology and Botany, University of Wisconsin, Madison, \\ Wisconsin, U.S.A.
}

SUMMARY: A new genus and species of the Acrasieae is described, and for this the binomial Acytostelium leptosomum is applied in recognition of its acellular sorophores and the diminutive proportions of its sorocarps. This slime mould has been isolated upon four occasions from soil and forest litter collected from deciduous forests within the United States. The vegetative stage of $A$. leptosomum, as that of the other cellular slime moulds of this Class, consists of the independent growth of myxamoebae which feed upon bacterial cells. The fruiting stage likewise duplicates that of other members of the Acrasieae in its early manifestations; but it differs markedly from these in its terminal phase, i.e. the construction of the mature fructification, or sorocarp. A. leptosomum is at present unique among these slime moulds in its capacity to produce a sorocarp with a non-cellular stalk. The morphogenetic process whereby this is accomplished is not thoroughly understood; nevertheless, a possible explanation of how the stalk may be formed without the expenditure of any cells is offered.

In his Monograph of the Acrasieae, representing the only comprehensive taxonomic treatment of these simple cellular slime moulds, Olive (1902) recognized three familes, namely: the Sappiniaceae, the Guttulinaceae, and the Dictyosteliaceae. The vegetative stage in each was noted to consist of independent free-living myxamoebae, whereas the fruiting stage was marked by the aggregation of these myxamoebae into multicellular organizations, termed pseudoplasmodia, and by their subsequent individual but co-ordinated differentiation to construct fructifications of varying complexity. Olive questioned whether the first of these families, represented only by the genus Sappinia Dangeard (1896), should be included since it showed no evidence of a well-defined pseudoplasmodium. The myxamoebae, in fruiting, simply collected on projections above the substratum, or as individuals, developed short pedicels which elevated the resting cells above the underlying substratum.

The second family, the Guttulinaceae, was thought to represent a limited advance. Following vegetative growth, the myxamoebae formed small if somewhat ill-defined psuedoplasmodia and in the ensuing fructifications exhibited some divergent cellular differentiation. Two genera were included. Guttulinopsis Olive (1901), regarded as the more primitive, formed small mound-like fructifications consisting simply of encysted individual myxamoebae, termed pseudospores. The cells of the stalk (or basal portion) were slightly elongate. The older genus, Guttulina Cienkowsky (1873), formed 
fructifications* consisting of spore masses, or sori, composed of rounded to angular spores with true walls, and stalks composed of wedge-shaped cells that were only slightly differentiated. The myxamoebae of both genera were characterized by lobose pseudopodia.

The third family, the Dictyosteliaceae, typified by Brefeld's genus Dictyostelium (1869) was, as the name implies, characterized by fructifications with prominent stalks which presented a net-like appearance, a condition resulting from the extreme vacuolation and compaction of their constituent cells. The vegetative myxamoebae possessed short, pointed (filose) pseudopodia. Four genera were included, and all were characterized by sorocarps exhibiting an abrupt separation into sterile supportive stalk tissue and strongly differentiated propagative cells, or spores. Two of these genera are to-day well known: Dictyostelium, distinguished by simple or irregularly branched sorophores bearing globose sori; and Polysphondylium (Brefeld, 1884), characterized by symmetrically branched (whorled) fructifications in which the main axis and each lateral branch bears a globose sorus. The genus Acrasis, known only from van Tieghem's description (1880), was reported to produce simple or clustered fruiting structures composed of a single tier of sterile, vacuolate stalk cells bearing a chain of echinulate spores. The remaining genus, Coenonia, likewise described by van Tieghem (1884) and not since rediscovered, was said to produce simple or branched fructifications. The main axis and each lateral branch (when present) bore a sorus in a small cupule composed of highly differentiated cells.

Thus in the families and genera which comprise the primitive class Acrasieae, Olive (1902) discerned an evolutionary sequence of increasingly advanced forms progressing from Sappinia through Guttulinopsis and Guttulina to Acrasis, Dictyostelium, Polysphondylium and Coenonia. Whereas markedly different levels of sorocarp complexity and cellular specialization are attained in the completed fructifications of these genera, the singular characteristic of the entire group is the co-ordinated behaviour and ultimate differentiation of individual amoeboid cells as the structural elements responsible for effecting whatever generic and specific developmental patterns are achieved.

A few years ago a diminutive slime mould was discovered which obviously belongs to the Acrasieae, yet differs from previously described genera by producing fructifications with non-cellular stalks, or sorophores. The vegetative stage consists of free-living myxamoebae and is indistinguishable from that of a Dictyostelium or a Polysphondylium; and the radiate pseudoplasmodia composed of streams of aggregating myxamoebae are essentially similar to those seen in the smaller species of Dictyostelium. Thus, there can be no doubt of its true relationship to the Acrasieae. Only in the terminal process of fructification does it differ basically from other genera already known, However,

* Harper introduced the term sorocarp for the mature fructification and sorophore for the supporting stalk in Dictyostelium (1926). In his study of Polysphondylium (1929) sorogen was used for the mass of undifferentiated myxamoebae of the completed fructification. These usages, together with sorus for the mass of differentiated spores (Zopf, 1885; Olive, 1901, 1902), have become generally adopted by students of the Acrasieae and will be used here. 
the ability of this slime mould to construct a supportive stalk without the apparent expenditure of any member cells represents such a major departure from the usual sorocarp building processes seen in the Acrasieae as to necessitate the establishment of a new genus to include it.

The binomial Acytostelium leptosomum, proposed in recognition of its acellular sorophores and the generally diminutive proportions of its sorocarps, was first applied to the new genus and species in a paper published earlier (Raper, 1956 b). The name was introduced to permit a brief comparison of the morphogenesis of this slime mould with that of other genera and species already known. It was not then possible to present an extended account or to include adequate technical descriptions of the new genus and species; nevertheless, a brief Latin description was published with accompanying photomicrographs to validate the use of the name. Much additional study has since been devoted to this unique member of the Acrasieae, and it is now possible to present full technical descriptions of the genus and species, together with accounts of its isolation, its cultivation, and the more salient features of its developmental history.

The presence of a cellular (Dictyo = net-like) stalk is so important a character of the Dictyosteliaceae that recognition of a new family, the Acytosteliaceae, is required also. However, since the new family would at present embrace only the single genus Acytostelium, the specifications for it would be identical with those of the genus, which are presented herewith:

\section{TECHNICAL DESCRIPTIONS}

Acytostelium Raper, nov.gen.*

In vegetativo statu, myxamoebae liberae bacteria edentes; in fructificativo statu, typica aggregatio myxamoebarum in radiatis, variis dimensionibus, pseudoplasmodiis et in subsequentibus sorocarpis cum acellularibus sorophoris terminales soros protantibus.

Vegetative stage consisting of free-living, independent myxamoebae which feed upon bacterial cells; fruiting stage characterized by the aggregation of such cells to form radiate pseudoplasmodia of varying dimensions and the subsequent development from these of sorocarps composed of acellular sorophores bearing masses of spores as terminal sori.

\section{Acytostelium leptosomum Raper, nov.gen. et sp.*}

Cultum ad $22-27^{\circ}$ in solido 'glucose + peptone' substrato (agar-agar) cum bacteriis, Aerobacter aerogenes vel Escherichia coli: myxamoebae vegetativae, liberae, uninucleatae, forma et dimensionibus variis, cum acutis pseudopodiis; pseudoplasmodia typice radiata, dimensionibus linearibus multum variis, sorocarpi gregarii, maxime delicati, cum erectis sorophoris, acellularibus, non ramificatis, plerumque $750-1500 \mu$. longis, $1 \cdot 0-2 \cdot 0 \mu$. diam., cum terminalibus soris; sori globosi, plerumque $\mathbf{3 0 - 5 0} \mu$. diam.; sori sphaerici, plerumque $5 \cdot 0-7 \cdot 0 \mu$. diam. 
$H a b . \mathrm{Ex}$ mucidis foliis in superiore solo, per deciduas silvas, isolatum, Illinois, Michigan et Wisconsin, U.S.A. (Typus isolatus: FG-12 a, Junio 1952).

Cultures grown upon dilute glucose + peptone or lactose + peptone agars in association with Aerobacter aerogenes or Escherichia coli at temperatures between 22 and $27^{\circ}$ : vegetative myxamoebae free-living, uninucleate, with pointed pseudopodia, variable in form and size, commonly 12-18 $\mu \times 7 \cdot 5-10 \mu$.; pseudoplasmodia typically radiate, varying greatly in linear dimensions; sorocarps gregarious, extremely delicate, consisting of erect, unbranched, acellular sorophores, commonly $750-1500 \mu$. long by $1 \cdot 0-2 \cdot 0 \mu$. diameter, bearing terminal sori; sori globose, mostly $30-50 \mu$. diameter; spores spherical commonly $5 \cdot 0-7 \cdot 0 \mu$. diameter. Myxamoebae often encysting as individuals to form microcysts.

Habitat. Isolated from leaf mould and surface soil from deciduous forests, Illinois, Michigan, Wisconsin, U.S.A. (Type strain FG-12a, isolated in June 1952).

\section{ISOLATION AND CULTIVATION}

Acytostelium leptosomum was first isolated in 1952 by the senior investigator and Miss Dorothy Fennell from leaf mould collected from a virginal deciduous forest of oaks, hickory, maple and associated trees and shrubs at Funk's Grove, Illinois. The slime mould was isolated by our conventional technique of streaking an aqueous suspension of the macerated source material on hayand thin hay-infusion agar plates (Raper, 1937, 1951), allowing the slime moulds to fruit, and then transplanting spores from the more isolated sori to fresh agar plates previously cross-streaked with Escherichia coli. We did not at the outset realize that we were isolating a new and unique slime mould, but instead suspected it of being an unusually diminutive Dictyostelium minutum.

Because of its small dimensions and the ephemeral nature of its sorocarps, Acytostelium leptosomum was with difficulty obtained in two-membered culture with various bacterial associates. Of these, Escherichia coli, generally used for other species, is satisfactory when careful attention is given to the composition of the substrate. The red-pigmented species Serratia marcescens can also be used with the resulting sorocarps developing a slight pinkish coloration suggestive of that seen more intensified in Dictyostelium discoideum and in Polysphondylium violaceum (Raper, 1937, 1951). The most generally satisfactory associate seemed to be Aerobacter aerogenes, and the new slime mould has been grown with this Gram-negative bacterium more often than with any other.

The slime mould may be grown by spotting or streaking a mixed inoculum of nutritive bacteria and spores on a suitable culture medium. However, we have generally pre-planted agar plates of the selected substrate with bacteria, either in the form of crossed streaks or as broad bands $(c .3 .0 \mathrm{~cm}$. wide), and subsequently added spores of the slime mould at the intersection of the crossed streaks or at 3 or 4 evenly spaced loci within the bands of bacterial growth in the other type of culture. In plates of the latter type the slime mould 
initiates growth at the points of inoculation and spreads radially from these, the resulting colonies attaining diameters of 3-4.5 cm. within 7-10 days. Radiate pseudoplasmodia typical of the Acrasieae normally appear at these centres after 3-4 days (Pl. 1, fig. 2) and others develop progressively outward from them as the frontiers of feeding myxamoebae advance (Pl. 1, fig. 1). Beautifully proportioned sorocarps generally develop from the first-formed pseudoplasmodia; those arising from aggregates formed subsequently commonly appear atypical or abortive. Not infrequently, sorocarps never develop from the aggregates which arise after the culture is 5-6 days old, presumably as a consequence of the accumulation of inimical but as yet unidentified products of the 'host's' metabolism.

Subsequent to the isolation of the original and type strain of Acytostelium leptosomum, no. FG-12a, cultures have been twice obtained from comparable leaf mould samples collected from deciduous forests in the Arboretum, University of Wisconsin, and once from the area of Gull Lake, Michigan. These appear to be like no. FG-12a in general dimensions and growth response on different substrata.

Acytostelium leptosomum has been cultivated upon a variety of substrates in two-membered cultures with Aerobacter aerogenes and with Escherichia coli. Results to date have been rather inconsistent, and it is difficult to recommend any single combination of culture medium and nutritive bacterium as optimal for its growth and fructification. The successful propagation of this slime mould, like that of all other members of the Acrasieae, is dependent upon the realization of a favourable cultural environment to which the composition of the substrate, the fermentative capacities of the bacterial associate, and the physical environment of temperature, $\mathrm{pH}$, etc., all make their separate and conjoint contributions--either favourable or unfavourable. However, two general conclusions can be drawn: Aerobacter aerogenes is generally a more satisfactory bacterial associate than Escherichia coli, and media of relatively low nutrient content are more productive of normal fructifications than more concentrated media of the types commonly employed for the cultivation of larger members of the Acrasieae (Raper, 1951). Present evidence would seem to indicate that the new genus and species is singularly sensitive to the cultural environment, this often varying in different areas of the same culture dish. We have not yet succeeded in obtaining a truly rich culture of this slime mould in which optimally proportioned sorocarps were abundantly produced.

Culture media. Many agar media containing low concentrations of lactose or glucose and peptone (Difco) or yeast extract (Difco) were investigated. Since it early became evident that the fructification of Acytostelium leptosomum was favoured by a mildly acid reaction, the carbon source was added generally at concentrations from 2 to 10 times $(w / w)$ that of the peptone or yeast extract to accentuate this condition. The compositions of some of the more favourable media, solidified with $1.5 \%(\mathrm{w} / \mathrm{v})$ agar (Difco), were:

(1) $0.1 \%(w / v)$ lactose $+0.1 \%(w / v)$ peptone. This medium was one of the first used and has served as an arbitrary standard for comparing other media. Colonies initiated as point inoculations in freshly implanted bands of bacterial 
growth attained a diameter of $1 \cdot 5-2 \cdot 0 \mathrm{~cm}$. within $7-10$ days. Small pseudoplasmodia were formed in the central area and from these a limited number of well-proportioned soroearps normally developed. Fruiting organizations seldom developed in marginal colony areas.

(2) $0.5 \%(\mathrm{w} / \mathrm{v})$ lactose $+0.05 \%(\mathrm{w} / \mathrm{v})$ peptone. This was a generally satisfactory medium; it supported fairly heavy growth and usually normal fructification. Colonies attained a diameter of $2 \cdot 0-2 \cdot 5 \mathrm{~cm}$. within 10 days and were marked by optimal fruiting in central areas, but with either normal or abnormal sorocarps developing outwards from these in localized situations. Microcysts were often produced in great abundance after one week.

(3) $0.5 \%(\mathrm{w} / \mathrm{v})$ lactose $+0.025 \%(\mathrm{w} / \mathrm{v})$ peptone. Results were much like those with the preceding except that bacterial and slime mould growth was less. Extensive non-fruiting pseudoplasmodia often developed secondarily to smaller primary fruiting aggregates. Microcyst formation was common.

(4) $0.1 \%(w / v)$ lactose $+0.05 \%(w / v)$ yeast extract. Total growth of bacteria and of slime mould was somewhat heavier than on the preceding medium; colonies reached a diameter $3 \cdot 0-3.5 \mathrm{~cm}$. in 10 days and were marked by optimal fruiting in the central areas, and by extensive pseudoplasmodia up to $1.5 \mathrm{~cm}$. in diameter nearer their margins.

(5) $0.05 \%(w / v)$ lactose $+0.025 \%(w / v)$ yeast extract. Growth of the bacteria and of the slime mould was limited, being less than on medium no. 4. Colonies of the slime mould attained a diameter of $3.5-4.0 \mathrm{~cm}$. in 10 days. Excellent fruiting generally occurred in central areas $1.0-1.5 \mathrm{~cm}$. in diameter, while outward from these extensive non-fruiting pseudoplasmodia often developed. Many of the illustrations for this paper were made from cultures of this type.

(6) $0.5 \%(\mathrm{w} / \mathrm{v})$ glucose $+0.1 \%(\mathrm{w} / \mathrm{v})$ peptone. Maximum growth of the slime mould and generally satisfactory fruiting was obtained on this medium. Within 10-14 days colonies attained a diameter of $4 \cdot 5-5.0 \mathrm{~cm}$., reaching the margin of the bacterial growth where massed sorocarps were produced. The latter were often suboptimal in proportions. Microcyst formation was sometimes very extensive and occurred in areas alternating with others wherein abundant sorocarps developed.

(7) $0.05(\mathrm{w} / \mathrm{v})$ glucose $+\mathbf{0 . 0 2 5} \%(\mathrm{w} / \mathrm{v})$ yeast extract. Slime mould colonies were commonly $4 \cdot 0-5 \cdot 0 \mathrm{~cm}$. diameter within 10-14 days with good sorocarp formation in central areas $\mathbf{1} \cdot \mathbf{0}-\mathbf{2} \cdot \mathbf{0} \mathrm{cm}$. in diameter; extensive non-fruiting pseudoplasmodia often developed in areas beyond these.

In addition to the above media, a dilute hay-infusion medium (thin-hay agar; Raper, 1951) was used successfully for the cultivation of Acytostelium leptosomum in association with Aerobacter aerogenes or Escherichia coli, Serratia marcescens, Pseudomonas fluorescens, Achromobacter sp. The amount of bacterial and slime mould growth was comparable to that obtained on medium no. 3 above. Colonies attained a diameter of $4 \cdot 0-5 \cdot 0 \mathrm{~cm}$. within 10 days, becoming confluent in the type of cultures employed. Well-proportioned sorocarps developed generally in central colony areas and at isolated islands outward from these. Relatively large non-fruiting pseudoplasmodia sometimes 
developed, but these rarely attained the dimensions cited above. Altogether, this was a favourable growth medium and it permitted fructification of the slime mould with a wider variety of bacterial associates than any other yet employed. However, its composition is unknown and not reproducible, and the brownish colour always associated with it interferes with microscopic observations. Except for initial isolations it was used less often than the compounded colourless agars listed above.

Hydrogen-ion concentration. It is not possible to cite a narrow and specific range of $\mathrm{pH}$ values as optimal for the growth and fructification of Acytostelium leptosomum since we have observed abundant, well-proportioned sorocarps upon substrates ranging from $\mathrm{pH} 4 \cdot 8$ to $6 \cdot 8$. As with other members of the Acrasieae, the $\mathrm{pH}$ range that permits myxamoebae to aggregate is slightly wider, and limited growth occurs from approximately $\mathrm{pH} 4 \cdot 5$ to $7 \cdot 6$. The values listed are, for the most part, those prevailing in unbuffered cultures at 610 days. Preliminary studies support the view that Acytostelium is not especially sensitive to $\mathrm{pH}$, and that the most favourable range is $c$. $\mathrm{pH} 5 \cdot 5-6 \cdot 0$.

Temperature. The optimal temperature for growth and sorocarp formation in Acytostelium leptosomum is approximately $25^{\circ}$. Growth may or may not take place at $30^{\circ}$ which appears to be about the maximum temperature tolerated. At $20^{\circ}$ growth and fructification was good, but both phenomena proceeded at slower rates than at $25^{\circ}$. At $15^{\circ}$ growth was very slow, the colonies seldom attaining a diameter greater than $1.0-1.5 \mathrm{~cm}$. within 10 days. Few pseudoplasmodia developed and from these only a limited number of small sorocarps were produced. Microcysts were regularly produced in great abundance, possibly due to the unfavourable physical environment.

\section{GROWTH AND MORPHOGENESIS}

\section{Spore germination}

The spores of Acytostelium leptosomum are typically spherical (Pl. 1, figs. 4, 5) and resemble those of Dictyostelium lacteum van Tieghem (1880), but differ from the capsule-shaped to reniform spores regularly seen in other species of Dictyostelium and in Polysphondylium. They vary considerably in size, ranging mostly from 5.0 to $6 \cdot 5 \mu$. diameter, but with individual spores from 4.5 to $7.5 \mu$. diameter. When compacted within the sorus they appear somewhat polygonal, but when viewed singly in an aqueous mount this aspect is no longer apparent. They possess a thin cellulose wall, and in germination do not release their myxamoebae by a splitting of the spore case as in most species of Dictyostelium and Polysphondylium but rather by the apparent dissolution of an area of the spore wall concurrent with the swelling of the spore content. Following germination, the empty spore case remains as a very delicate hyaline structure that exhibits no evident birefringence.

\section{Vegetative growth}

Upon germination the emergent myxamoeba begins to feed upon bacterial cells and divides. The vegetative phase of Acytostelium leptosomum thus begun 
consists, as in all of the Acrasieae, of the separate and independent growth of free-living myxamoebae which increase in numbers by repeated divisions until a large population is built up and the available food supply is exhausted. As this occurs, the fruiting stage is initiated by the aggregation of the previously unoriented myxamoebae into pseudoplasmodia, from each of which several minute sorocarps subsequently develop. The vegetative myxamoebae of the new genus and species (Pl. 2, fig. 10) exhibit no structural or behavioural characteristics that distinguish them from those of a species of Dictyostelium or of Polysphondylium. They are inconstant in form, ranging from irregularly elongate, through wedge-shaped and broadly triangular to more or less rounded. Pseudopodia are filose rather than lobose, and these seldom exceed in length more than one-quarter the overall diameter of the myxamoeba. Whereas these may occur at any position on the surface of the amoeboid cell, they are understandably most prominent at the advancing edge of cells in active motion. The vegetative myxamotbae vary appreciably in mass, and differences in linear dimensions are often pronounced. Whereas the latter must be interpreted with considerable caution, they are of comparative value, and in $A$. leptosomum these range from $18-20 \times 8 \cdot 0-6 \cdot 5 \mu$. in the more elongate cells, from 12-16 $\times 12-8 \mu$. in those which are expanded and roughly triangular, and from 8.5 to $12.5 \mu$. in individuals that are more nearly round. Each vegetative cell contains a single nucleus which is difficultly discernible in the living state, and this is normally central within the endoplasm. The actively motile cell exhibits a marginal zone of clear, non-granular ectoplasm most pronounced at the anterior edge, and the small filopodia represent irregular extensions of this material. The main body of the vegetative myxamoeba is composed of a finely granular endoplasm which contains, in addition to the nucleus, food vacuoles enclosing bacteria in various stages of digestion and one or more excretory vacuoles. When present in numbers greater than one, the excretory vacuoles usually coalesce before being discharged in a rhythmic pattern which may vary from cell to cell.

Under optimal cultural conditions the myxamoebae characteristically enter a pseudoplasmodium at the close of the vegetative stage and subsequently contribute to the formation of one of the several sorocarps which rise from it. Not infrequently, however, particularly in older and less favourable cultures, the vegetative cells enter a resting stage as individuals, forming microcysts (Blaskovics \& Raper, 1957) by the deposition of thin protective cellulose walls. In extreme cases, under conditions not at present understood, almost all the myxamoebae become so encysted, producing a broad and virtually continuous layer of rounded inactive cells which never become parts of any fruiting organization. In other instances (see later), very large pseudoplasmodia may develop which do not proceed to sorocarp formation, and in these the constituent myxamoebae may in time form microcysts. Whereas the microcysts of most cellular slime moulds (e.g. Polysphondylium pallidum Olive and Dictyostelium polycephalum Raper as reported by Blaskovics \& Raper; see above) differ markedly in appearance from true spores, those of Acytostelium leptosomum do not exhibit this distinction. The microcysts, like the spores, are spherical. 
Considered as a cell population, however, they average slightly larger than the spores. The dimensions of individual cells of the two types overlap throughout most of their separate ranges, and in a mixed population it is difficult to distinguish between them. Occasionally much larger spheroid to ovoid cells ranging up to $12-15 \mu$. in diameter are observed in older cultures; the origin and significance of these are not presently known. The walls of the microcysts appear light purple or bluish when stained with chloroiodide of zinc, and when then viewed with polarized light exhibit a marked birefringence, possibly less intense than that of the spores. In $A$. leptosomum the microcyst appears to germinate in the same manner as true spores and the released myxamoeba leaves behind a thin, hyaline case from which apparently a portion of the wall has been dissolved.

\section{Pseudoplasmodia}

At the end of the vegetative stage, which is normally coincident with the exhaustion of the food supply (Pl. 2, fig. 6), the previously independent and unoriented myxamoebae become conspicuously elongate in the direction of emergent centres toward which they aggregate by their co-ordinated movements, probably prompted and controlled by a diffusible chemotactic agent comparable to that reported for Dictyostelium discoideum (Bonner, 1947 et seq.; Shaffer, 1953, 1956a, $b$; 1957; Sussman, Lee \& Kerr, 1956). As this process continues the inflowing myxamoebae collect into progressively larger converging streams (Pl. 2, figs. 8, 9) producing radiate pseudoplasmodia (Pl. 1, figs. 1, 2) basically similar in pattern and structure to the wheel-like aggregates formed in species of Dictyostelium and Polysphondylium. The degree of cell elongation during the aggregative process varies in different pseudoplasmodia and within different streams and areas of the same organization. To an appreciable extent the degree of such elongation may be correlated with the rates of movement of individual cells; in the more actively streaming myxamoebae the length of a cell is not uncommonly 5-6 times its greatest diameter, dimensions of 25-30 $\times 5-6 \mu$. being common.

The pseudoplasmodia of Acytostelium leptosomum vary greatly in size, ranging from less than $1 \mathrm{~mm}$. to several $\mathrm{cm}$. in diameter. There is reason to believe that the latter ( $\mathrm{Pl}$. 2, fig. 11) represent a somewhat abnormal development, for such expansive organizations generally form in marginal areas of older colonies after smaller aggregates have developed near the sites of inoculation. Furthermore, the large pseudoplasmodia seldom give rise to normal sorocarps, whereas the smaller, first-formed aggregates characteristically produce these in varying numbers up to twenty-five or more (Pl. 1, fig. 3). Not uncommonly, the very large organizations never progress beyond the stage of cell aggregation, and in time the constituent myxamoebae may form microcysts as already described or they may eventually disintegrate in situ.

Under optimal conditions, and in cultures initiated by point inoculations, pseudoplasmodia begin to develop within 3 days from the time of implantation and may continue to form for 7 days or more thereafter, being removed 2 or 3 days behind the advancing front of vegetative myxamoebae (Pl. 2, fig. 6). 
The first-formed aggregates are always radially symmetrical in pattern, whereas those subsequently developed assume the outlines dictated by the areas from which the contributory myxamoebae are drawn. As aggregation proceeds, and often many hours before the process is complete, numerous minute papillae appear on the surface of the central, slightly elevated portion of the pseudoplasmodium, and in each of these the construction of a sorocarp is soon begun. To a degree seldom observed in other members of the Acrasieae, aggregation and culmination proceed simultaneously within the same overall community of cells (Pl. 2, fig. 7). The events taking place in any particular part of this community obviously reflect the stage of maturity currently attained by the cells of that area. It is suggested that a chemotactic stimulus capable of attracting the myxamoebae initially may prove inadequate to direct further integration and differentiation essential to sorocarp formation. On the other hand, quite different regulatory substances may be operative in aggregation and in culmination.

We have at present no satisfactory explanation for the formation of the very large and virtually centreless pseudoplasmodia in Acytostelium leptosomum (Pl. 2, fig. 11), which often persist for days. On the one hand they may originate from a definite and seemingly normal primary centre from which very long, rebranched, and more or less anastomosing streams extend outward for $1 \mathrm{~cm}$. or more (Pl. 2, fig. 11). More commonly, no definite centre can be distinguished and the component streams seem merely to focus on a general area adjacent to sites where earlier and more nearly normal pseudoplasmodia were formed. Not infrequently, only a general area of attraction can be discerned and streams simply originate and disappear in areas where equally dense populations of myxamoebae remain unaggregated and unoriented. For the former case it was suggested (Raper, 1956 b) that an Acytosteliumacrasin is produced, and that this stimulates the myxamoebae to aggregate in characteristic fashion, after which the stimulus fades and the cells are left leaderless-yet they do not disperse. For the latter cases, where no definable centres are obvious, an alternative explanation might suggest that extensive fields of myxamoebae may arrive almost simultaneously at a receptive stage, but the points of Acytostelium-acrasin production are so numerous as to preclude the ascendance of any well-defined centres. In any case, we are reasonably certain that the formation of these large aggregates reflects a measure of cultural adversity.

\section{Sorocarps}

The uniqueness of Acytostelium leptosomum becomes apparent only during the process of sorocarp formation or culmination, as Bonner (1944) designated this terminal phase of development. Whereas the pseudoplasmodial stage possesses certain distinctive features, particularly the very large non-fruiting aggregates, even these are not regarded as basically dissimilar to the pseudoplasmodia of other genera. The continuing influx of late-arriving cells concurrently with the differentiation into sorocarps of others previously assembled is most striking in this slime mould, yet these same phenomena are seen to 
overlap in varying degrees in almost all members of the Acrasieae. This is particularly true in two of the smaller species of the genus Dictyostelium, D. lacteum van Tieghem (1880) and D. minutum Raper (1941). Furthermore, a gregarious habit comparable with that of Acytostelium leptosomum is regularly observed in these slime moulds also, differing from the new genus and species principally in the production of fewer sorocarps from a single primary pseudoplasmodium. Thus, no developments occur in $A$. leptosomum before the actual construction of the sorocarp, which would necessitate the creation of a new genus.

The completed sorocarp of Acytostelium leptosomum consists of a very delicate unbranched tubular sorophore supporting a globose sorus at its terminus. The dimensions of such fructifications vary in different cultures and in different areas of the same culture, depending apparently upon localized environmental conditions. However, their dimensions never exceed certain maxima which we believe to reflect the greatest number of myxamoebae that can collaborate successfully in sorocarp formation. In well-proportioned sorocarps the sorophores commonly range between 750 and $1500 \mu$. in length by $1 \cdot 0-2 \cdot 0 \mu$. in diameter, although shorter structures are commonly observed and others up to $1.8 \mathrm{~mm}$. in length are occasionally seen. Sorophore diameters seldom fall outside the stated range, even in structures that are obviously abnormal. The diameter of the sori commonly range between 20 and $50 \mu$. but smaller spore masses are often seen and an occasional sorus may reach $60 \mu$. diameter. As in species of Dictyostelium and Polysphondylium, the sorus consists of a mass of spores suspended in cohesive slime which maintains its globular form.

The sorophore of Acytostelium leptosomum is of special interest since it is acellular and must, therefore, represent a secreted structure in its entirety. This is in marked contrast to the sorophore of the Dictyosteliaceae which consists of strongly vacuolated and compacted cells which differentiate within a previously secreted tubular 'mold' termed the sorophore sheath. This sheath of cellulose is deposited extracellularly at the appropriate circular locus within the developing sorocarp, or sorogen, by a continually changing group of anteriorly placed myxamoebae*. In Acytostelium leptosomum the stalk itself is believed to be of comparable origin, but with the important difference that the secreted cellulose is deposited by anteriorly placed myxamoebae into an extremely narrow intracellular trough centrally positioned in the apical portion of the sorogen. Because of this, the lumen of the sorophore is so small as to preclude the entrance or entrapment therein of any myxamoebae and so all of the cell population is available for the production of spores. There can be little question but that this represents, in many ways, a distinct advance over Dictyostelium and Polysphondylium where a substantial fraction (c. 20-25\% in Dictyostelium discoideum) of the total population is sacrificed in the construction of supportive tissue, namely the sorophore. On the other hand, the new genus is possibly handicapped by this very process of cell conservation,

* For details of sorocarp formation in Dictyostelium see Raper \& Fennell (1952) and Bonner et al. (1955). 
for it probably limits the dimensions to which the sorophores and sorocarps can be constructed.

The first indication of sorocarp formation is the appearance of minute papillae upon the upper surface of the central area of the aggregating pseudoplasmodium (Pl. 3, fig. 14). Such incipient sorogens increase in height and soon may be observed to be free of the main body of inflowing myxameobae and to be supported on very delicate stalks (Pl. 2, fig. 7; Pl. 3, figs. 12, 13). By this time the separate masses of fructifying myxamoebae have assumed an irregularly fusiform shape, which with minor variations is generally maintained until sorophore formation is almost completed. Figures 12 and $13(\mathrm{Pl} .3)$ and fig. 20 (Pl. 4) illustrate this point; fig. 15 (PI. 3), on the other hand, shows a sorogen shortly before the beginning of spore maturation in which the apical portion is more nearly rounded. An interesting feature of all these stages, and one that can be detected quite early (Pl. 3, fig. 14), is the transverse orientation of the myxamoebae which comprise the sorogens. This condition is most clearly seen in figs. 20 and 15, and it poses some very intriguing problems concerning the mechanics of sorocarp building in this singular slime mould.

In their study of sorocarp formation in Dictyostelium, Raper \& Fennell (1952) pointed out that cells oriented in a transverse direction, such as the myxamoebae comprising the apical tip of the developing sorocarp of Dictyostelium discoideum, could not contribute effectively to the lifting force responsible for raising the sorogen. It was concluded that this force had its origin in the vacuolating (and hence enlarging) cells entrapped within the lengthening sorophore sheath, and that its effectiveness stemmed from the exertion of substantial pressure against the cells directly above the open end of the sorophore sheath and through them upon the slime covering that continuously enveloped the apical area until the completion of culmination. In $D$. discoideum the remainder of the sorogen, including the mass of differentiating spores of later stages, simply adhered to the apical portion by cohesive forces and advanced with it. The lengthening sorophore of Actyostelium leptosomum contains no vacuolating cells; therefore, the effective lifting force must be sought elsewhere, and this cannot reasonably be considered to arise from the transversely oriented myxamoebae (Pl. 4, fig. 20). The following hypothesis is tentatively advanced: through the co-ordinated behaviour of the anteriorly positioned myxamoebae a very narrow and vertically elongate intracellular channel is maintained centrally in the apical portion of the sorogen. Into this space the surrounding cells secrete cellulose (or its precursors), while the continuous accumulation of this substance anteriorly, coupled with the centripetal restraining force exerted laterally by the closely packed cells, results in a forward pressure which is exerted upon the slime encased cells that close the channel at its anterior end. Thus the tip is advanced and, as in Dictyostelium, the remainder of the body follows, being drawn forward by cohesive forces. It is believed significant that in $A$. leptosomum a sorogen with an apical tip of sharply reduced diameter such as that seen in Dictyostelium has not been observed in a developing sorocarp. Apparently, spore maturation occurs rapidly, and present information would indicate that this process is not initiated until 
the formation of the sorophore has been completed. Thus the entire sorogen in this new genus may act during culmination in a manner comparable with the apical tip of a developing sorocarp of Dictyostelium, except that it loses none of its cellular members in constructing the sorophore.

There is, we believe, substantial support for the foregoing hypothesis. Plate 4, fig. 20 shows quite clearly the characteristic transverse orientation of the myxamoebae in a developing sorocarp. The accompanying illustration (fig. 21), photographed with polarized light, shows equally well the extension of the delicate sorophore far into the anterior third of the sorogen. Figures 22 and 23 (Pl. 5) illustrate the close horizontal compacting of the myxamoebae in this portion of the sorogen and also the effective closure anteriorly of any hypothetical channel within this area by strategically positioned terminal myxamoebae, or 'cap cells'. In figs. 24 and 25 (Pl. 5) the horizontally flattened, wedge-shaped cells of the apical region are seen dissociated, while in fig. $\mathbf{2 6}$ a small circular segment of the same region shows such cells in their normal positions as viewed vertically from the bottom or the top (?) of the sorogen. Significantly, this segment shows a minute opening at its centre which we think could represent the postulated open secretory channel seen in cross section.

The extremely delicate nature of the sorophore in proportion to the size of the spore mass that it supports is well illustrated in $\mathrm{Pl}$. 1, fig. 4, while in the adjacent photomicrograph (fig. 5) this is re-emphasized by showing its diameter to be only a fractional part of one of the hundreds of spores that it supports. Figure 16 (Pl. 3) shows some of these structures bent to reveal their tubelike nature. Figure 17 shows the base of one of these, here protrayed as broadening and thinning downward; but, as seen in situ, this portion of the stalk is expanded radially on the agar in the pattern of a flaring skirt and gives the sorophore a considerable measure of vertical support. Finally, the cellulosic nature of the sorophores, and of the spore walls as well, is substantiated by figs. 18 and $19(\mathrm{Pl} .4)$, where a preparation was treated with chloroiodide of zinc and subsequently photographed under normal and polarized light.

Considering the fact that the erect sorocarps of Acytostelium leptosomum are apparently never branched, one might surmise that the myxamoebae which constitute a rising sorogen are committed to the formation of one and only one fruiting structure. Such is not the case. If the sorogen of an incompleted sorocarp topples over and touches the agar surface sorophore formation ceases forthwith, the mass of undifferentiated myxamoebae reorganizes into one or more secondary fruiting organizations, and a small but thoroughly normal sorocarp subsequently arises from each of the fractional parts. In one example, a sorophore $1200 \mu$. in length had been constructed prior to such sorogen-to-agar contact, and thereafter two smaller erect sorocarps with sorophores 650 and $525 \mu$., respectively, developed. In another instance, a sorogen which had already produced a sorophore $1400 \mu$. in length segmented into four parts following contact with the agar, and from these parts minute sorocarps having sorophores $350,425,450$ and $525 \mu$. in length subsequently developed. As one would anticipate, the primary and secondary sorophores were not interconnected. Only in the source of their constitutive cells could 
the latter sorogens be considered continuous with the first; the intercellular organizations leading to their formation were, of course, new. The behaviour of these fruiting masses is not reported to suggest their uniqueness. Quite the contrary, for when the developing sorocarp of any cellular slime mould is seriously disturbed, adjustments and reorganization of its cellular components regularly follow, the extent of these changes being determined by the severity of the dislocations that prompted them. In the case of Dictyostelium mucoroides Brefeld (1869) or D. purpureum Olive (1901) mere contact of an intact sorogen with the agar surface would not lead to a comparable reorganization, for such contact commonly occurs and it is via this device that the developing sorocarps build long sorophores in the direction of light. On the other hand rupture of the sorogen in these latter species, whether by natural or induced causes, concurrent with agar contact would be followed by the fragmentation of the primary mass into two or more smaller fruiting organizations. The difference in degree of response exhibited by the contrasting genera can undoubtedly be correlated with (1) the thickness and tenacity of the slime envelope that surrounds the sorogens in the two genera, (2) the dimensions of the sorophores in relationship to those of the parent sorogens, and (3) the strengths of the forward building forces generated by the developing sorophores in relationship to the resistance offered by the cell masses resting upon an agar surface. Finally we record that in Acytostelium leptosomum, as in species of Dictyostelium, if the constituent cells of a sorogen are disassociated in the presence of nutritive bacteria they will again resume the vegetative phase and fruiting will not recur until the normal cycle has been repeated.

Thus it is seen that Acytostelium leptosomum nov.gen. et sp. normally exhibits many of the characteristics common to all of the Acrasieae, and particularly so of those genera that comprise the Dictyosteliaceae. On the other hand, the construction of its sorocarps with their inordinately thin acellular sorophores, however produced, clearly sets the genus and species apart from all previously known members of the Acrasieae and adds new dimensions to earlier concepts of what initially independent cells may achieve through progressive integration and co-ordinated differentiation.

This investigation was supported in part by a research grant, NSF-C-612, from the National Science Foundation and in part by a research grant, $\mathrm{C}-2119$ (C) $\mathrm{M}$ and G, from the National Cancer Institute, of the National Institutes of Health, Public Health Service.

The writers are indebted to Professor C. E. Vezina of the Department of Bacteriology, Oka Agricultural Institute (University of Montreal), La Trappe, Quebec, Canada, for preparing the Latin diagnoses, and to Professor Const. J. Alexopoulos, University of Iowa, Iowa City, Iowa, for deriving from the Greek the binomial applied to the new slime mould.

\section{REFERENCES}

Blaskovics, J. C. \& RAPER, K. B. (1957). Encystment stages of Dictyostelium. Biol. Bull. Wood's Hole, 113, 58.

Bonner, J. T. (1944). A descriptive study of the development of the slime mold Dictyostelium discoideum. Amer. J. Bot. 31, 175. 
BonNer, J. T. (1947). Evidence for the formation of cell aggregates by chemotaxis in the development of the slime mold Dictyostelium discoideum. J. exp. Zool. 106, 1 .

Bonner, J. T. (1949). The demonstration of Acrasin in the later stages of the development of the slime mold Dictyostelium discoideum. J. exp. Zool. 110, 259.

Bonner, J. 'T., Chiquoine, A. D. \& Kolderie, M. Q. (1955). A histochemical study of differentiation in the cellular slime molds. J. exp. Zool. 130, 133.

Bonner, J. T. \& Slifkin, M. K. (1949). A study of the control of differentiation: The proportions of stalk and spore cells in the slime mold Dictyostelium discoideum. Amer. J. Bot. 36, 727.

Brefeld, O. (1869). Dictyostelium mucoroides. Ein neuer Organismus aus der Verwandschaft der Myxomyceten. Abh. Senckenb. naturf. Ges. 7, 85.

Brefeld, O. (1884). Polysphondylium violaceum und Dictyostelium mucoroides nebst Bemerkungen zur Systematik der Schleimpilze. Untersuch. Gesammtgebiete Mykologie. pt. 6, 1.

Cienkowsky, L. (1873). Guttulina rosea. Trans. Bot. Sect. 4th Meeting Russian Naturalists at Kazan, 1873.

Dangeard, P. A. (1896). Contribution a l'étude des Acrasiees. Botaniste, 5 e serie, 1.

HARPer, R. A. (1926). Morphogenesis in Dictyostelium. Bull. Torrey bot. Club, 53, 229.

Harper, R. A. (1929). Morphogenesis in Polysphondylium. Bull. Torrey bot. Club. $56,227$.

Olive, E. W. (1901). A preliminary enumeration of the Sorophoreae. Proc. Amer. Acad. Arts Sci. 37, 333.

Olive, E. W. (1902). Monograph of the Acrasieae. Proc. Boston Soc. nat. Hist. $30,451$.

RAPER, K. B. (1935). Dictyostelium discoideum, a new species of slime mold from decaying forest leaves. $J$. agric. Res. 50, 135.

RAPER, K. B. (1937). Growth and development of Dictyostelium discoideum with different bacterial associates. J. agric. Res. 55, 289.

RAPER, K. B. (1940). The communal nature of the fruiting process in the Acrasieae. Amer. J. Bot. 27, 436.

RAPER, K. B. (1941). Dictyostelium minutum, a second new species of slime mold from decaying forest leaves. Mycologia, 33, 633.

RAPER, K. B. (1951). Isolation, cultivation, and conservation of simple slime molds. Quart. Rev. Biol. 26, 169.

RAPER, K. B. (1956a). Dictyostelium polycephalum n.sp.: a new cellular slime mould with coremiform fructifications. J. gen. Microbiol. 14, 716.

RAPER, K. B. (1956b). Factors affecting growth and differentiation in simple slime molds. Mycologia, 48, 169.

RAPER, K. B. \& Fennell, D. I. (1952). Stalk formation in Dictyostelium. Bull. Torrey bot. Club, 79, 25.

Shaffer, B. M. (1953). Aggregation in cellular slime moulds: in vitro isolation of Acrasin. Nature, Lond. 171, 975.

Shaffer, B. M. (1956a). Properties of Acrasin. Science, 123, 1172.

ShafFer, B. M. $(1956 b)$. Acrasin, the chemotactic agent in cellular slime moulds. J. exp. Biol. 33, 645 .

ShafFEr, B. M. (1957). Aspects of aggregation in cellular slime moulds. I. Orientation and chemotaxis. Amer. Nat. 91, 19.

Sussman, M., Lee, F. \& KerR, N. S. (1956). Fractionation of acrasin, a specific chemotactic agent for slime mold aggregation. Science, 123, 1171.

Tieghem, P. van (1880). Sur quelques myxomycètes a plasmode agrégré. Bull. Soc. bot. Fr. 27, 317.

Tieghem, P. van (1884). Coenonia, genre nouveau de Myxomycètes a plasmode agrégé. Bull. Soc. bot. Fr. 31, 303.

Zopf, W. (1885). Die Pilzthiere oder Schleimpilze. Encyk. Naturwissenschaften, Handbuch der Botanik 3, (2), 1-174, Breslau. 


\section{EXPLANATION OF PLATES}

\section{Plate 1}

\section{General characteristics of Acytostelium leptosmum}

Fig. 1. Culture growing on lactose $(0 \cdot 1 \%)+$ yeast extract $(0.05 \%)$ agar in association with Aerobacter aerogenes; incubation 10 days at $24-26^{\circ}$. Note the clustered sorocarps at the colony centre and the developing pseudoplasmodia in the marginal area. $\times 12$.

Fig. 2. A single psuedoplasmodium showing the typical radiate pattern assumed by the aggregates which develop initially; sorogens are just beginning to form at the dense centre. $\times 32$.

Fig. 3. A cluster of sorocarps in various stages of development arising from a single pseudoplasmodium such as that shown in the preceding figure. $\times 32$. (Reprinted from Mycologia (1956), 48, 180.)

Fig. 4. A single sorus with its very thin, unbranched sorophore; the sorus is flattened by the pressure of the coverglass. Preparation stained with erythrosin in aqueous phenol $(5 \%) . \times 280$.

Fig. 5. Spores stained with erythrosin in aqueous phenol together with two sorophores. $\times 1300$.

\section{Prate 2}

\section{Pseudoplasmodium formation in Acytostelium leptosomum}

Fig. 6. A portion of a colony growing in association with Aerobacter aerogenes on lactose $(0.1 \%)+$ peptone $(0.05 \%)$; incubation 10 days at $24-26^{\circ}$. Note the uninvaded portion of the bacterial streak (upper right), the front of feeding myxamoebae and, in the older portion of the colony, the developing pseudoplasmodia. $\times 10$.

Fig. 7. Two aggregating pseudoplasmodia from which sorocarps are already developing. $\times 30$.

Fig. 8. Peripheral area of an aggregating pseudoplasmodium showing the origin of the inflowing streams of myxamoebae; stained with trypan blue in aqueous phenol (5\%). $\times 120$.

Fig. 9. Details of a portion of an inflowing stream from a pseudoplasmodium like the preceding; note the orientation and elongate form of the myxamoebae. $\times 625$.

Fig. 10. Vegetative, free-living (unoriented) myxamoebae, similarly killed and stained and photographed in situ. $\times 700$.

Fig. 11. Large, non-fruiting pseudoplasmodia developed on lactose $(0 \cdot 1 \%)+$ yeast extract $(0.05 \%)$ agar in association with Aerobacter aerogenes; incubation 10 days at 24-26. $\times 8$.

\section{Plate 3}

\section{Sorocarp formation in Acytostelium leptosomum}

Fig. 12. A fructifying organization showing the continued aggregation of myxamoebae (lower right) concurrent with the development of several sorocarps. $\times 80$.

Fig. 13. An enlarged view of three of the sorogens seen in the preceding figure; note their characteristic fusiform shape. $\times \mathbf{3 4 0}$.

Fig. 14. A very young sorogen at about the beginning stage of sorphore formation; note that the myxamoebae in the terminal area already show evidence of transverse orientation. $\times 650$.

Fig. 15. A sorogen in an advanced stage of sorocarp formation. Note particularly the conspicuous transverse orientation of the myxamoebae, and the rounded outline of the apical portion of the body. $\times 650$.

Fig. 16. Typical sorophores seen in their median areas showing the manner in which they bend, indicating their tube-like structure. $\times 1280$.

Fig. 17. Expanded base of a sorophore. Seen in situ, this portion of the stalk is spread out on the agar in the form of a flaring skirt and supports the sorophore in an upright position. $\times 1280$. 


\section{Plate 4}

Sorocarp formation in Acytostelium leptosomum

Fig. 18. Sorophores and spores stained with chloroiodide of zinc. The sorophores, and to a lesser extent the spores, stain blue with this reagent, indicating their cellulosic nature. $\times 120$.

Fig. 19. The same photographed with polarized light. Note the strong birefringence of the sorophores and the less intense birefringence of the spore walls, further confirming their cellulosic nature. $\times 120$.

Fig. 20. A developing sorocarp. Note the transverse orientation of the constituent myxamoebae and the extension of the sorophore into the apical area. $\times 825$. (Reprinted from Mycologia (1956), 48, 197.)

Fig. 21. The same structure photographed under polarized light. Note that the birefringence is evident almost to the terminus of the sorogen. $\times 825$.

\section{Plate 5}

\section{Sorophore formation in Acytostelium leptosomum}

Fig. 22. Terminus of a sorogen killed and lightly stained with iodine in $70 \%$ alcohol, as seen in surface view without distortion. Note particularly the cell at the apex, termed the 'cap cell'. $\times 1350$.

Fig. 23. Terminus of a sorogen stained with erythrosin in aqueous phenol $(5 \%)$ mounted under a coverglass, hence compressed. Note the flattened cells and particularly the 'cap cell' with its nucleus. $\times 1350$.

Fig. 24. Broken terminus of a sorogen stained with trypan blue in aqueous phenol, showing the horizontally flattened, semicircular cells characteristic of this area. $\times \mathbf{7 0 0}$.

Fig. 25. Dissociated cells from the subterminal portion of a second sorogen treated in a similar way. Note the wedge-shaped pattern of the cells from this area. $\times 700$.

Fig. 26. A small intact disk of cells from a sub-terminal position at which site sorophore formation takes place. It is suggested that the sorophore is formed by the secretion of cellulose (or its percursors) into a small, centrally positioned lumen, here seen in crosssection. $\times 700$. 
Journal of General Microbiology, Vol. 18, No. 1
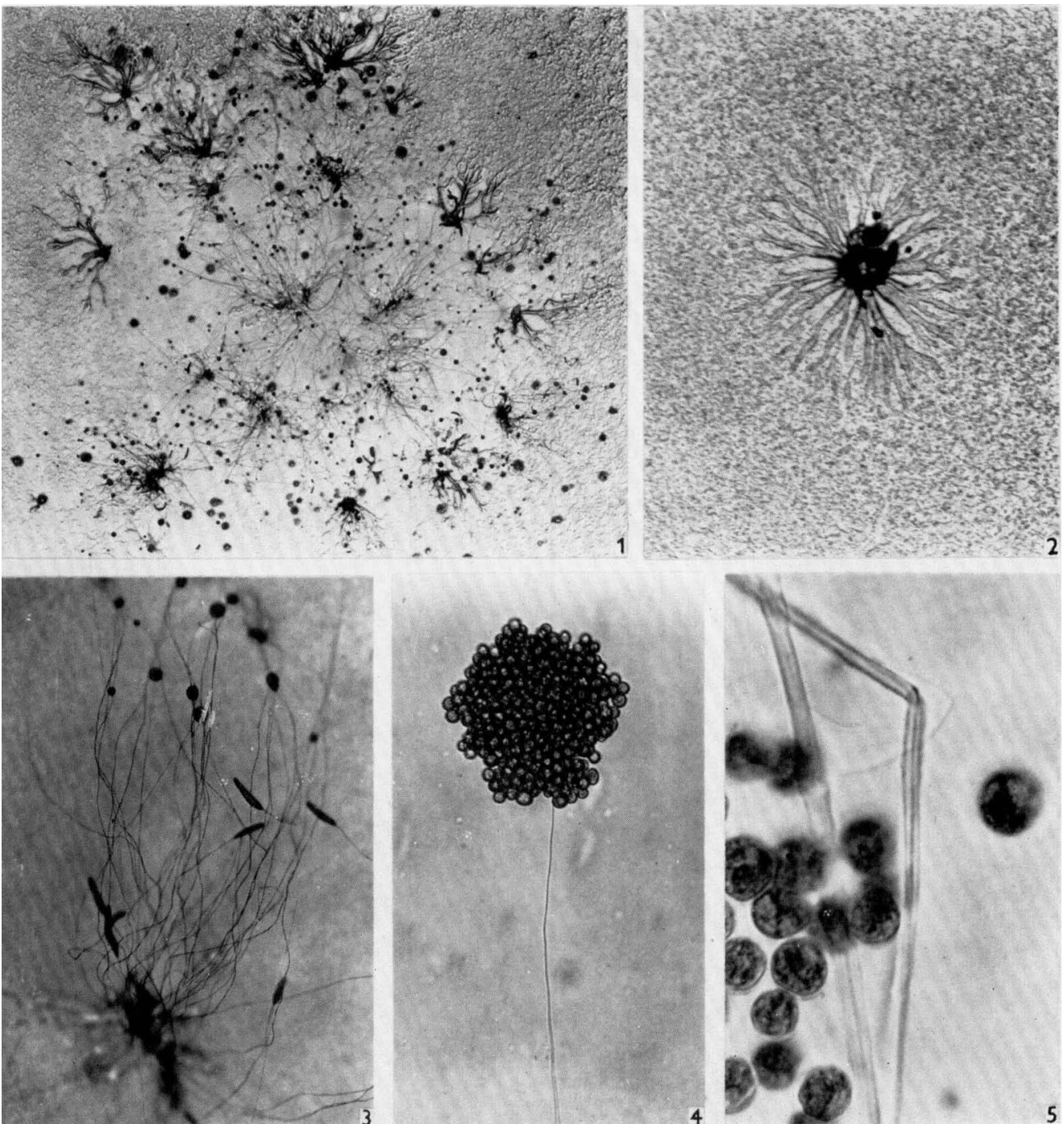

4

K. B. Raper \& M. S. Quinlan-Acytostelium Leptosomum. Plate 1

(Facing p. 32) 
Journal of General Microbiology, Vol. 18, No. 1

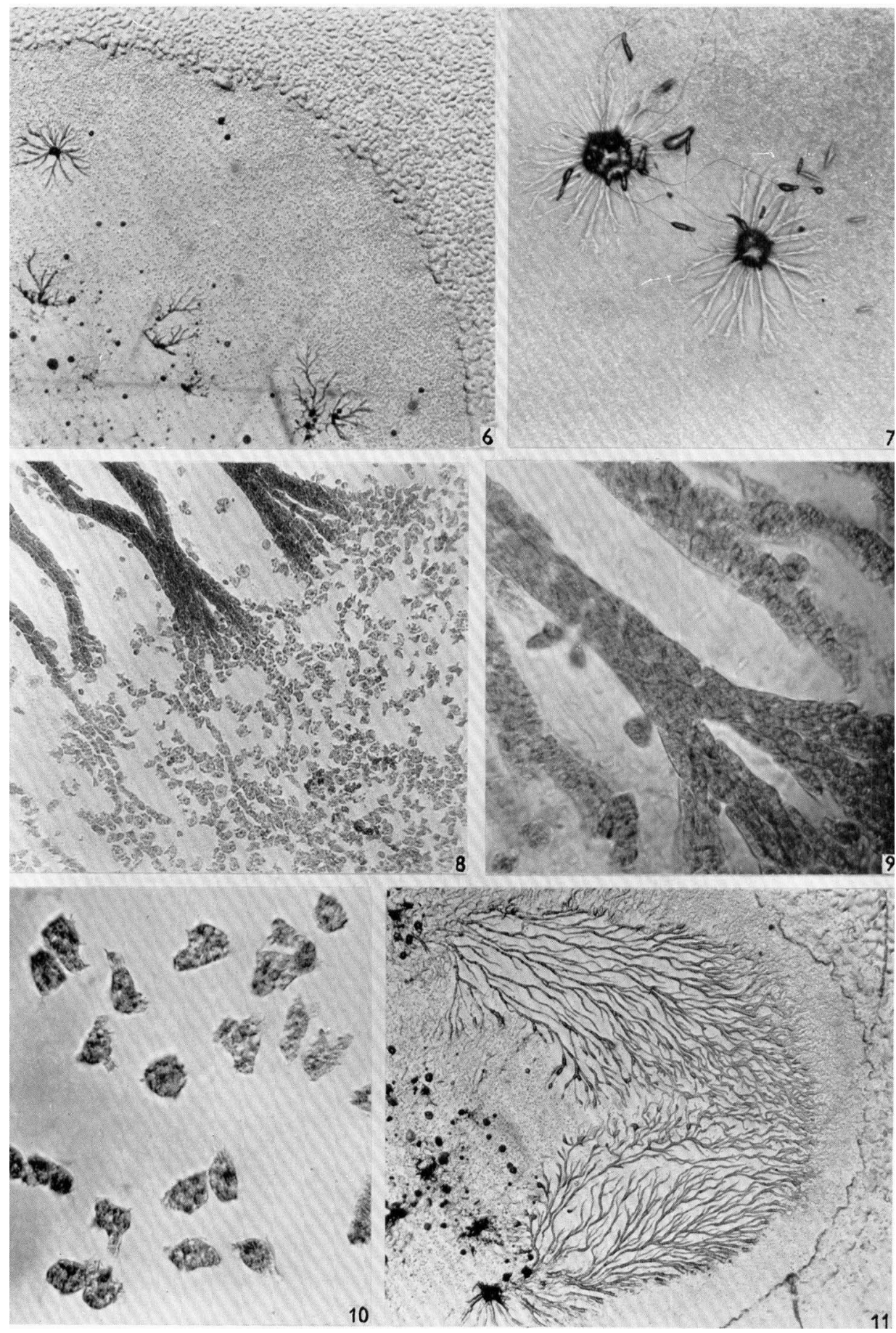

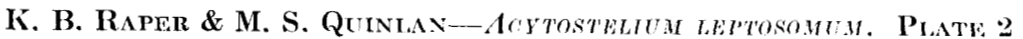


Journal of General Microbiology, Vol. 18, No. 1
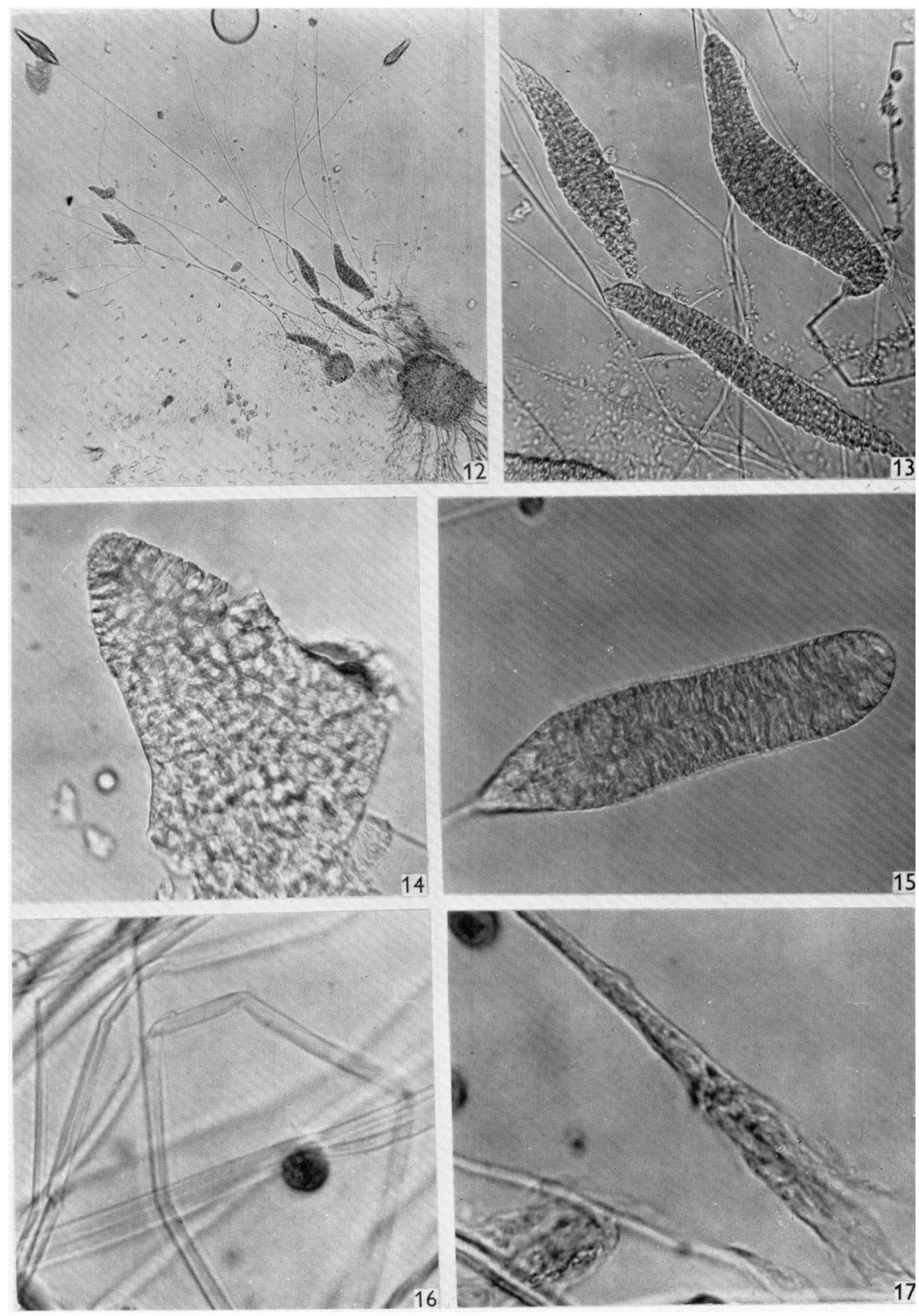

K. B. Raper \& M. S. Quinian-Aogtostelem heptogomom. Prate 3 
Journal of General Microbiology, Vol. 18, No. 1
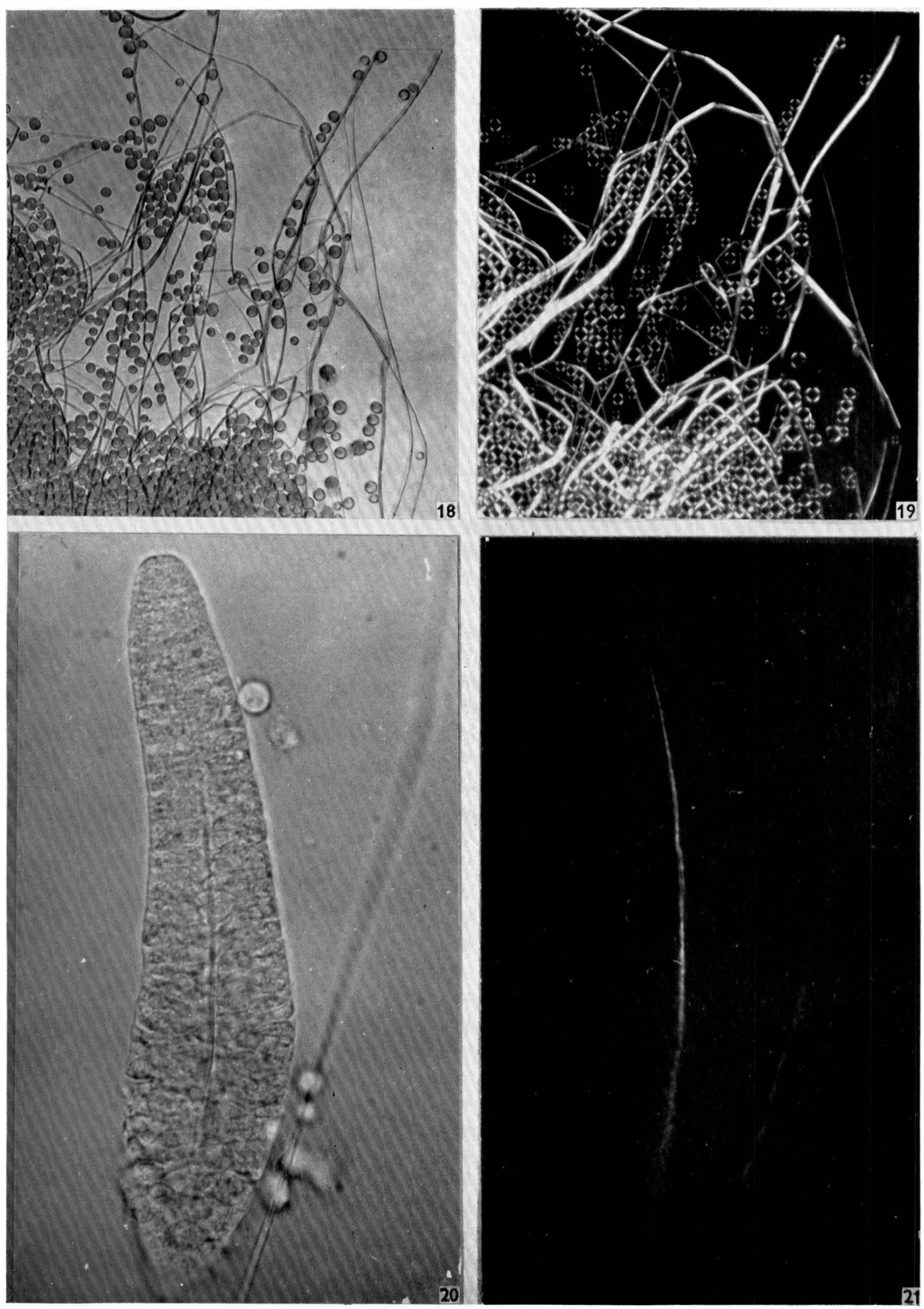

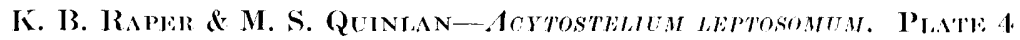


Journal of General Microbiology, Vol. 18, No. 1

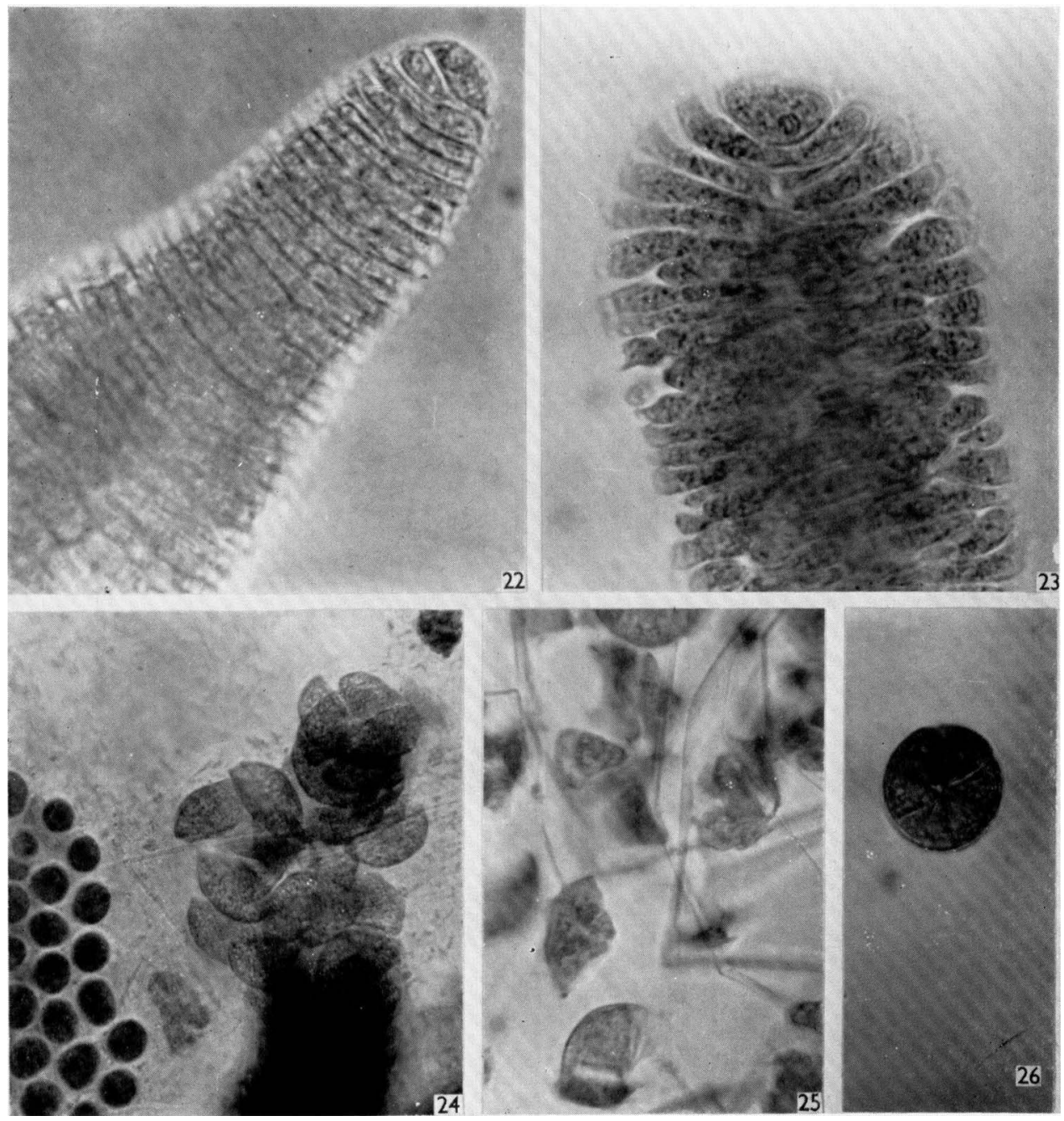

K. B. Rapler \& M. S. Quinlan-Acytosteltem leptusomem. Plate 5 